И.Н.Виноходова ${ }^{2}$, Ю.С.Ландышев ${ }^{1}$, О.А.Мажкарова ${ }^{2}$

\title{
Зависимость изменения показателей легочно-сердечной, почечной гемодинамики и функции внешнего дыхания у больных бронхиальной астмой при лечении глюкокортикостероидами
}

1 - ГОУ ВПО "Амурская государственная медицинская академия Минздравсоцразвития РФ": 675000, Амурская обл., Благовещенск, ул. Горького, 95;

2 - ОГУЗ "Амурская областная клиническая больница Федерального агентства по здравоохранению и социальному развитию": 675028, Амурская обл., Благовещенск, ул. Воронкова, 26

\section{I.N.Vinokhodova, Yu.S.Landyshev, O.A.Mazharova \\ A relationship between cardiorespiratory and renal haemodynamics and lung function in patients with bronchial asthma treated with inhaled corticosteroids}

\begin{abstract}
Summary
This research was aimed at comprehensive evaluation of clinical and functional features of cardiorespiratory and renal haemodynamics in patients with bronchial asthma of different severity treated with inhaled corticosteroids. Ninety six patients with confirmed diagnosis of mild, moderate or severe asthma were examined in comparison with 21 healthy individuals (the control group). Cardiorespiratory and renal haemodynamics and lung function were evaluated initially and then were monitored during the treatment with inhaled corticosteroids.

Results demonstrated no difference in pulmonary artery mean pressure and peripheral renal vascular resistance between mild asthma patients and the controls. In patients with moderate and severe asthma, peripheral renal vascular resistance was increased in the arch and in the interlobular arteries resulted from the increased pulmonary artery mean pressure. Treatment of moderate asthma patients led to renal hemodynamic parameters approached to those in the control group. In patients with severe asthma, parenchymatous vascular haemodynamics showed only a tendency to improvement. The results substantiated a reasonability of comprehensive evaluation of cardiorespiratory and renal haemodynamics and lung function in asthma patients that could provide timely diagnosis of early-stage disorders of renal haemodynamics, choice of adequate therapeutic approach and reduction in treatment duration.

Key words: bronchial asthma, renal hemodynamics, pulmonary artery mean pressure, lung function.
\end{abstract}

\section{Резюме}

Целью настоящего исследования явилось комплексное изучение клинико-функциональных особенностей легочно-сердечной и почечной гемодинамики у больных бронхиальной астмой (БА) различной степени тяжести на фоне приема глюкокортикстероидов (ГКС). Были обследованы 96 пациентов с верифицированным диагнозом БА. Контрольная группа состояла из 21 человека, сопоставимых по полу и возрасту. Анализировались показатели сердечного и почечного кровотока, функции внешнего дыхания (ФВД) и их динамические изменения при лечении ГКС. В результате проведенных исследований установлено, что у больных с легким течением БА в период обострения заболевания среднее давление в легочной артерии и индексы периферического сопротивления в почечных сосудах не отличались от контрольной группы. При среднетяжелой и тяжелой БА с повышением среднего давления в легочной артерии повышались индексы периферического сопротивления сосудов почек на уровне дуговой и междольковой артерии. После лечения ГКС у больных БА средней тяжести показатели почечного кровотока практически приблизились к уровню контрольной группы; у больных тяжелой БА изменения на уровне паренхиматозных сосудов имели лишь тенденцию к улучшению. Установлена целесообразность комплексного исследования легочно-сердечной, почечной гемодинамики и показателей ФВД, позволяющего своевременно диагностировать ранние признаки нарушения почечного кровообращения, избрать адекватную терапевтическую тактику и сократить сроки лечения больных.

Ключевые слова: бронхиальная астма, кровоток в почках, среднее давление в легочной артерии, максимальная объемная скорость выдоха на уровне 50 \% форсированной жизненной емкости легких.

Бронхиальная астма (БА) представляет глобальную проблему для здравоохранения. Распространенность БА в разных странах мира колеблется от 1 до $18 \%$ в общей популяции [1]. Современный научный прогноз свидетельствует о том, что в ближайшие несколько 10-летий тенденция к увеличению количества больных сохранится [2]. Актуальность данной проблемы обусловлена ростом количества больных с тяжелыми формами и увеличением числа смертельных исходов [3-5]. Особый интерес представляет изучение у больных БА гемодинамики почек, учитывая их роль в обеспечении циркуляторного и метаболического гомеостаза [6]. Почки играют ведущую роль в поддержании постоянства водно-электролитного состава и объема жидкостей внутренней среды, обеспечивая тем самым оптимальные условия жизнедеятельности организма. Наиболее перспективными методами в диагностике нарушений кровотока в малом и большом кругах кровообращения в последние годы является ультразвуковое (УЗ) исследование [7]. 
УЗ-исследование отличается от других методов сочетанием широкого спектра диагностических возможностей, высокой безопасностью, относительно низкой стоимостью и доступностью, поэтому на сегодняшний день оно составляет основу диагностики в нефрологии $[8,9]$. Следует отметить, что в отечественной и зарубежной литературе имеются лишь единичные сообщения о нефрологических аспектах при патологии легких [10-13].

Целью настоящего исследования явилось комплексное изучение клинико-функциональных особенностей внутрисердечной и почечной гемодинамики у больных БА фоне приема глюкокортикостероидов (ГКС) при различной степени тяжести и длительности заболевания.

\section{Материалы и методы}

В специализированном пульмонологическом отделении Амурской областной клинической больницы были обследованы 96 больных БА в возрасте от 24 до 68 лет (средний возраст $-46,0 \pm 10,0$ лет). Контрольная группа состояла из 21 здорового человека (средний возраст $-40,0 \pm 15,0$ лет). Все больные находились на диспансерном наблюдении в Амурском реабилитационном астма-центре и получали базисную терапию согласно рекомендациям "Глобальной стратегии по диагностике и лечению БА" (GINA 2007). А в период обострения дополнительно назначались ингаляционные глюкокортикостероиды (иГКС): бенакорт, альдецин и беклоджет. Больные обследовались в динамике развития патологического процесса: до и после проведенного курса лечения (при поступлении больного в стационар и через 12-14 дней после начала лечения). Из исследования исключались больные, у которых в анамнезе были заболевания почек или легких с массивными плевральными сращениями и пневмофиброзом. В 1-ю группу были включены 18 (18,7 \%) больных с легкой персистирующей астмой (БАЛТ). 2-ю группу составили $27(28,2 \%)$ пациентов с персистирующей астмой средней степени тяжести (БАСТ). 3-я группа состояла из 51 больного $(53,1 \%)$ тяжелой астмой (БАТТ).

Функция внешнего дыхания (ФВД) определялась на аппарате Fucuda (Япония). Анализировалась максимальная объемная скорость выдоха на уровне 50 \% форсированной жизненной емкости легких $\left(\mathrm{MOC}_{50}\right)$. Газовый состав крови определяли на газоанализатоpe AVL-950 (Австрия). У3-исследование было выполнено на аппарате "Алока-5000" (Япония). Почки обследовались методом дуплексного сканирования датчиком конвексного формата, работающим в частотном диапазоне от 2,5 до 6 МГц. Исследование проводилось из абдоминального и заднелатерального доступов, в B-, D-режимах. Комплексное УЗ-исследование сердца проводили в M-, B-, D-режимах по стандартной методике, предложенной в 1981 г. Американской ассоциацией кардиологов. Применяли секторные датчики с частотой 3,5 МГц.

Измерения почечного кровотока производились на уровне паренхиматозных ветвей почечных арте- рий: междолевых, дуговых, междольковых в верхнем, нижнем и среднем сегментах почки. У обследованных пациентов не обнаружено асимметрии почечного кровотока, в связи с этим представлены фактические данные только по одной правой почке. Количественный анализ включал в себя определение показателей, связанных с периферическим сосудистым сопротивлением: резистивный (Ri) и пульсационный (Pi) индексы, определение которых не требует соблюдения угла сканирования. С помощью импульсной допплерографии определяли среднее давление в легочной артерии (СрДЛА).

Полученные результаты обрабатывались стандартными статистическими методами. Количественные параметры, характеризующиеся нормальным распределением, представлены в виде $M \pm m$. Различия считали достоверными при $p \leq 0,05$.

\section{Результаты и их обсуждение}

В результате проведенных исследований установлено, что показатели сердечного и почечного кровотоков изменяются в зависимости от степени тяжести БА и имеют ряд особенностей в период обострения заболевания и в период ремиссии. У больных БА с легким контролируемым течением заболевания при умеренной обструкции бронхов, нормальных показателях $\mathrm{PaO}_{2}$ и $\mathrm{PaCO}_{2}$ в период обострения СрДЛА и индексы периферического сопротивления

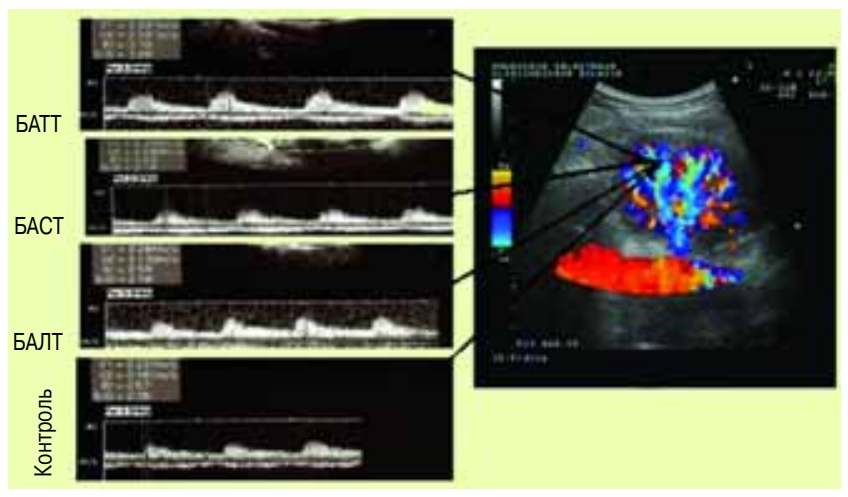

Рис. 1. Дуплексное исследование кровотока у больных БА на уровне дуговых артерий

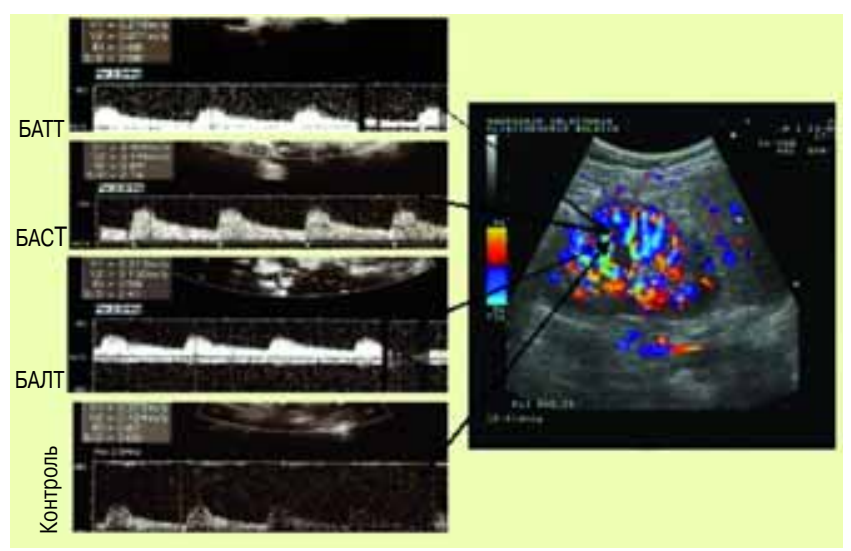

Рис. 2. Дуплексное исследование кровотока у больных БА на уровне междолевых артерий 
Динамика спирографических показателей, параметров газового состава крови, легочно-сердечной и почечной гемодинамики у больных БА $(M \pm m)$

\begin{tabular}{|c|c|c|c|c|c|c|c|c|}
\hline Показатели & $\begin{array}{c}\text { Ri междолевой } \\
\text { артерии }\end{array}$ & $\begin{array}{l}\text { Рі междолевой } \\
\text { артерии }\end{array}$ & $\begin{array}{l}\text { Ri дуговой } \\
\text { артерии }\end{array}$ & $\begin{array}{l}\text { Рі дуговой } \\
\text { артерии }\end{array}$ & $\mathrm{MOC}_{50}$ & СрДЛА & $\mathrm{PaO}_{2}, \mathrm{k} \Pi \mathrm{a}$ & $\mathrm{PaCO}_{2}, \mathrm{k} \Pi \mathrm{a}$ \\
\hline Здоровые & $0,59 \pm 0,003$ & $1,0 \pm 0,01$ & $0,55 \pm 0,004$ & $0,96 \pm 0,008$ & $88,6 \pm 8,21$ & $14,39 \pm 0,1$ & $10,78 \pm 0,25$ & $5,12 \pm 0,07$ \\
\hline \multicolumn{9}{|l|}{ БАЛТ } \\
\hline до лечения & $0,61 \pm 0,01$ & $1,05 \pm 0,04$ & $0,57 \pm 0,004$ & $1,01 \pm 0,006$ & $72,2 \pm 3,3$ & $16,36 \pm 0,06^{* *}$ & $10,85 \pm 0,24$ & $5,02 \pm 0,04$ \\
\hline после & $0,55 \pm 0,02$ & $0,98 \pm 0,01$ & $0,55 \pm 0,004$ & $0,98 \pm 0,006$ & $85,3 \pm 6,4$ & $13,64 \pm 0,1$ & & \\
\hline \multicolumn{9}{|l|}{ БАСТ } \\
\hline до лечения & $0,60 \pm 0,004$ & $1,10 \pm 0,01^{* * *}$ & $0,61 \pm 0,004^{* * *}$ & $1,27 \pm 0,07^{* * *}$ & $38,8 \pm 4,6^{* * *}$ & $16,81 \pm 0,38^{* *}$ & $9,45 \pm 0,44^{\star}$ & $5,29 \pm 0,04^{* *}$ \\
\hline после & $0,60 \pm 0,003$ & $1,07 \pm 0,008^{* * *}$ & $0,55 \pm 0,004$ & $1,12 \pm 0,01^{* *}$ & $61,6 \pm 4,1^{* *}$ & $14,8 \pm 0,46$ & & \\
\hline \multicolumn{9}{|l|}{ БАТT } \\
\hline до лечения & $0,68 \pm 0,005^{* * *}$ & $1,24 \pm 0,007^{* * *}$ & $0,69 \pm 0,004^{\star * *}$ & $1,27 \pm 0,007^{* * *}$ & $25,9 \pm 3,7^{* * *}$ & $21,89 \pm 0,17^{* * *}$ & $8,01 \pm 0,24^{\star \star *}$ & $5,76 \pm 0,14^{\star \star *}$ \\
\hline после & $0,64 \pm 0,004^{* * *}$ & $1,21 \pm 0,01^{* * *}$ & $0,66 \pm 0,005^{\star * *}$ & $1,23 \pm 0,008^{* * *}$ & $30,1 \pm 4,1^{* * *}$ & $20,42 \pm 0,22^{* * *}$ & & \\
\hline
\end{tabular}

Примечание: достоверность различий показателей по отношению к контрольной группе: ${ }^{*}-p<0,05 ;{ }^{* *}-p<0,01 ;{ }^{* * *}-p<0,001$.

в почечных сосудах не отличались от контроля. При БАСТ, с увеличением степени обструкции бронхов, снижением суммарной вентиляции легких и $\mathrm{PaO}_{2}$, повышением $\mathrm{PaCO}_{2}$ и СрДЛА, соответственно изменялись показатели гемодинамики почек. При этом достоверно повышались индексы периферического сопротивления на уровне дуговой и междольковой артерий. У больных БАТТ в период обострения, на фоне изменения показателей газового состава крови, внутрисердечного кровотока и вентиляционной функции легких, наблюдалось более выраженное повышение Ri и Рі в ветвях почечной артерии (таблица, рис. 1, 2).

После лечения у больных БАСТ показатели почечного кровотока значительно улучшились и практически приблизились к уровню контроля. У больных БАТТ изменения на уровне паренхиматозных сосудов имели лишь тенденцию к улучшению.

Для установления различий между группами по нескольким вариантам значений одновременно был применен метод многомерной статистики - дискри-

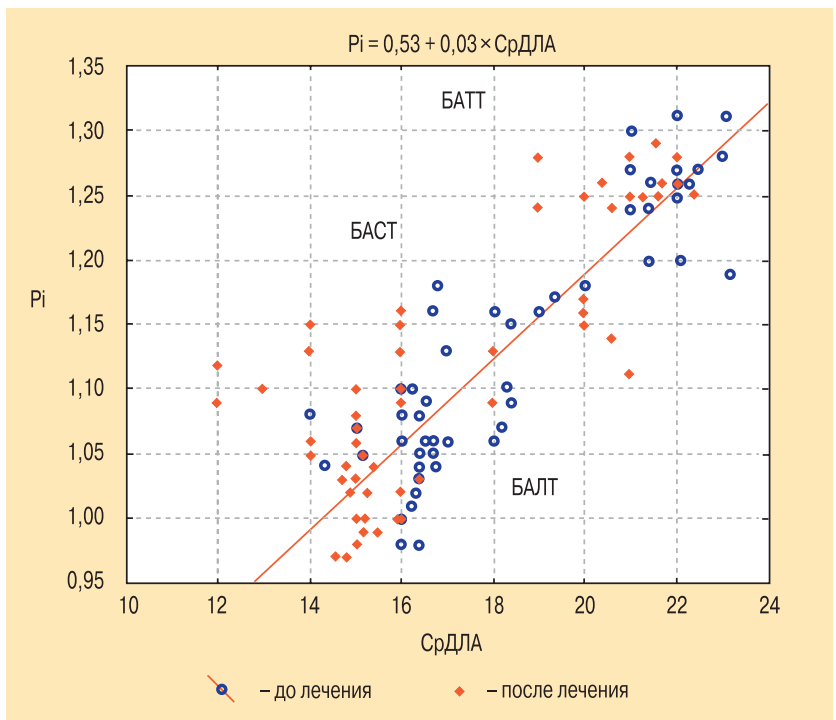

Рис. 3. Корреляционное поле в 2-мерном пространстве: показатели зависимости Рі на уровне междолевых артерий и СрДЛА у больных БАЛТ, БАСТ и БАТТ минантный анализ. Целью его использования являлось выявление такой линейной комбинации переменных, которая оптимально разделила бы рассматриваемые группы. На основании данных спирометрии, допплерографического исследования сосудов почек и эхокардиографии (ЭхоКГ) были отобраны параметры, коррелирующие между собой, и использованы для построения дискриминантного уравнения. Были использованы $\mathrm{MOC}_{50}$, Pi на уровне междолевых артерий и СрДЛА. Для дискриминации все значения переменных в группах были выражены в интервальной шкале, из анализа исключались линейно зависимые переменные, значения которых не подчинялись многомерному нормальному закону распределения.

На рис. 3 показано, что зависимость между Pi и СрДЛА прямая, возрастающая $\left(r_{s}>0\right)$. Низкие показатели СрДЛА соответствовали невысоким значениям пульсационного индекса и принадлежали больным БАЛТ. Средние значения были выявлены у больных БАСТ. У пациентов с БАТТ отмечены высокие показатели Рі и СрДЛА.

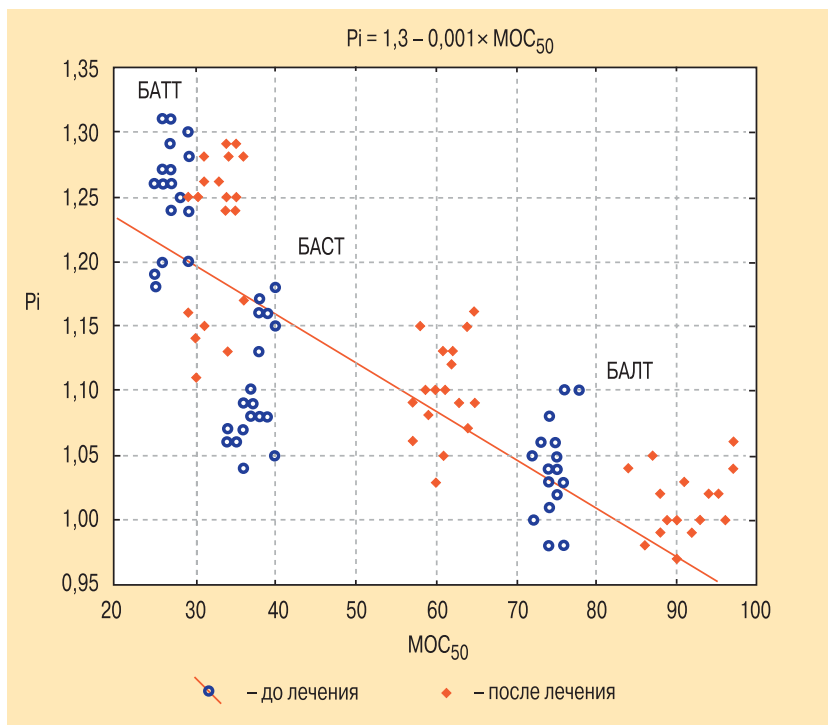

Рис. 4. Корреляционное поле в 2-мерном пространстве: показатели зависимости Рі на уровне междолевых артерий и $\mathrm{MOC}_{50}$ у больных БАЛТ, БАСТ и БАТТ 
Зависимость между Рі и MOC $_{50}$ обратная, убывающая $\left(r_{s}<0\right)$. Низкие значения $\mathrm{MOC}_{50}$ соответствовали высоким значениям Рі у больных БАТТ (рис. 4). Значения $\mathrm{MOC}_{50}$ повышаются при уменьшении степени тяжести заболевания, при этом Рі снижается.

С целью анализа зависимости Рі на уровне междолевых артерий от $\mathrm{MOC}_{50}$ и СрДЛА была построена множественная регрессионная модель:

$$
\mathrm{Pi}^{0}=0,68 \times \text { СрДЛА }-0,3 \times \text { MOC }_{50}
$$

Полученная модель хорошего качества $\left(\mathrm{R}^{2}=0,84\right)$. Уравнение модели статистически надежно $\left(\mathrm{F}_{\text {эмп }}=\right.$ 148 , при $\left.\mathrm{F}_{0,99}(2 ; 55)=5,1, p<0,01\right)$. Оно позволяет ранжировать показатели по степени влияния на результат. Наибольшее значение имеет коэффициент при показателе СрДЛА, что позволяет сделать заключение о его значительном влиянии на $\mathrm{Pi}$, по сравнению с $\mathrm{MOC}_{50}$.

Для установления степени тяжести БА с учетом клинических симптомов, параметров ФВД, допплерографического исследования сосудов почек и ЭхоКГ были получены канонические уравнения дискриминации статистически значимых для разделения групп факторов (рис. 5):

$$
\begin{aligned}
& \mathrm{df}_{1}=0,45 \times \mathrm{Pi}+0,13 \times \text { СрДЛА }-0,99 \times \text { MOC }_{50} ; \\
& \mathrm{df}_{2}=-0,16 \times \mathrm{Pi}+1,1 \times \text { СрДЛА }+0,2 \times \text { МOC }_{50},
\end{aligned}
$$

где $\mathrm{df}_{1}$ - граница между БАЛТ с БАСТ и БАТТ, при $\mathrm{df}_{1}<0$ - пациенты относятся к группе БАЛТ, при $\mathrm{df}_{1}>0$ - к объединению групп БАСТ и БАТТ; $\mathrm{df}_{2}-$ граница между БАСТ и БАТТ,

при $\mathrm{df}_{2}<0$ - пациенты относятся к группе БАСТ, при $\mathrm{df}_{2}>0-\mathrm{k}$ группе БАТТ.

Эти функции позволяют считать, что $\mathrm{MOC}_{50} \mathrm{~B} \mathrm{df}_{1}$, имея наибольшее значение коэффициента, играет определяющее значение в постановке диагноза БАЛТ. А для постановки диагноза БАСТ и БАТТ в $\mathrm{df}_{2}$ определяющее значение имеет СрДЛА.

Применение результатов дискриминантного анализа в алгоритме обследования пациентов дает воз-

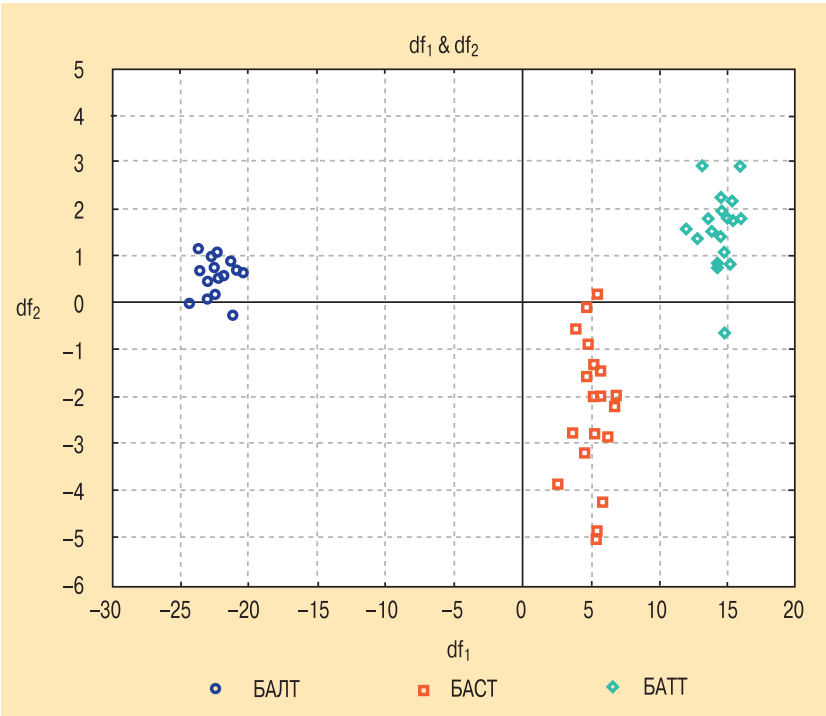

Рис. 5. Дискриминантный анализ можность прогнозировать степень тяжести заболевания.

Патогенетическая базисная терапия позволила полностью контролировать БА у больных БАЛТ в $100 \%$ случаев. При БАСТ удалось достичь контроля в $60 \%$, при БАТТ - в $37 \%$ случаев. Больные с тяжелым течением БА наименее подвержены достижению контроля над заболеванием. Это связано с длительностью заболевания, наличием осложнений, стероидозависимым вариантом БА.

Проведение комплексного исследования показателей импульсной допплерографии почечных сосудов в сочетании с ЭхоКГ при патогенетическом лечении больных БА различной степени тяжести способствует выявлению ранних признаков нарушения почечного кровообращения и позволяет избрать адекватную лечебную тактику.

\section{Заключение}

1. Включение в комплексную терапию иГКС у больных БА оказывает положительное влияние на показатели почечной гемодинамики и повышает эффективность лечения.

2. Предложенные нами формулы дискриминантного анализа в алгоритме обследования пациентов позволяют прогнозировать обострение заболевания и могут служить критерием для формирования групп высокого риска по развитию нефропатии.

\section{Литература}

1. Глобальная стратегия лечения и профилактики бронхиальной астмы. Национальный институт здоровья США. Национальный институт сердца, легких и крови. Пересмотр 2007. М.: Атмосфера; 2007.

2. Чучалин А.Г. Актуальные вопросы пульмонологии (Белая книга). Рус. мед. журн. 2004; 12 (2): 53-59.

3. Ландышев Ю.С. Бронхиальная астма (нейроэндокринная система, иммунитет, клиника, диагностика, лечение). Благовещенск: Полисфера; 2006.

4. Mehta V., Stokes J.R., Berro A. et al. Time-dependent effects of inhaled corticosteroids on lung function, bronchial hyperresponsiveness, and airway inflammation in asthma. Ann. Allergy Asthma Immunol. 2009; 103 (1): 31-37.

5. Izuhara K., Ohta S., Shiraishi H. et al. The mechanism of mucus production in bronchial asthma. Curr. Med. Chem. 2009; 16 (22): 2867-2875.

6. Лелюк В.Г., Лелюк С.Э. Физиологические аспекты и ультразвуковая картина почечной гемодинамики в норме и при артериальной гипертензии: Метод. пособие. М.; 2005.

7. Науменко Ж.К., Неклюдова Г.В. Возможности эхокардиографии в пульмонологической практике. Атмосфера. Пульмонол. и аллергол. 2009; 1: 7-10.

8. Глазун Л.О., Полухина Е.В.Ультразвуковое исследование сосудов почек: Учеб.-метод. пособие для практ. врачей, врачей ультразвуковой диагностики, терапевтов, нефрологов и урологов. Хабаровск; 2003. 5-16.

9. Kalantarinia K., Belcik J.T., Patrie J.T., Wei K. Real-time measurement of renal blood flow in healthy subjects using contrast enhanced ultrasound. Am. J. Physiol. Renal. Physiol. 2009; 297: 1129-1134. 
10. Hassoun T.H., Lie M.L., Grigoryev D.N. et al. Kidney ischemia-reperfusion injury induces caspase-dependent pulmonary apoptosis. Am. J. Physiol. Renal. Physiol. 2009; 297: 125-137.

11. Karoli N.A., Rebrov A.P. Vasoregulating activity of the endothelium and pulmonary hypertension. Ter. Arkh. 2004; 76 (12): 39-44.

12. Kadowitz P.J., Majid D.S., Matavelli L.C., Navar L.G. Renal hemodynamic and excretory responses to intra-arterial infusion of peroxynitrite in anesthetized rats. Am. J. Physiol. Renal Physiol. 2009; 296: 170-176.

13. Плясухина И.Б., Ушаков В.Ф. Возможности цветового допплеровского картирования в изучении состояния почек у больных бронхиальной астмой. В кн. Наука и инновации XXI века: Материалы V Открытой окружной конф. молодых ученых. Сургут: СурГУ; 2005.

\section{Информация об авторах}

Виноходова Ирина Николаевна - врач отделения ультразвуковой диагностики ОГУЗ "Амурская областная клиническая больница Федерального агентства по здравоохранению и социальному развитию"; тел.: (4162) 42-95-31; e-mail: iranikvin@bk.ru

Ландышев Юрий Сергеевич - д. м. Н., проф., зав. кафедрой госпитальной терапии ГОУ ВПО "Амурская государственная медицинская академия Минздравсоцразвития РФ", заслуженный деятель науки РФ, заслуженный врач РФ; тел.: (4162) 52-27-13

Мажарова Ольга Алексеевна - К. м. н., зав отделением ультразвуковой диагностики ОГУЗ "Амурская областная клиническая больница Федерального агентства по здравоохранению и социальному развитию"; тел.: (4162) 42-95-31

Поступила 05.04.10 (С) Коллектив авторов, 2010 удк 616.248-085.357-092 